\title{
Iron Indices and Mortality in Maintenance Hemodialysis Patients
}

\author{
Saeko Kumon',2, Yoichiro Tanaka, ${ }^{1,2}$, Kazuo Kimura ${ }^{1,2}$, Takako Onuki, ${ }^{1,2}$, Shigeru Otsubo ${ }^{1,3}$, \\ Kosaku Nitta ${ }^{1}$
}

${ }^{1}$ Department of Medicine, Towa Hospital, Tokyo, Japan

${ }^{2}$ Department of Medicine, Kidney Center, Tokyo Women's Medical University, Tokyo, Japan

${ }^{3}$ Department of Blood Purification, Sangenjaya Hospital, Tokyo, Japan

Email:knitta@twmu.ac.jp

How to cite this paper: Kumon, S., Tanaka, Y., Kimura, K., Onuki, T., Otsubo, S. and Nitta, K. (2018) Iron Indices and Mortality in Maintenance Hemodialysis Patients. International Journal of Clinical Medicine, 9, 454-466.

https://doi.org/10.4236/ijcm.2018.95039

Received: April 24, 2018

Accepted: May 19, 2018

Published: May 22, 2018

Copyright (c) 2018 by authors and Scientific Research Publishing Inc. This work is licensed under the Creative Commons Attribution International License (CC BY 4.0).

http://creativecommons.org/licenses/by/4.0/

\section{Open Access}

\begin{abstract}
Background: The relationship between the iron indices and mortality in maintenance hemodialysis (MHD) patients has remained unclear. We performed a retrospective, observational cohort study to investigate the relationships between serum ferritin levels and mortality in MHD patients. Methods: MHD outpatients $(n=150)$ were followed up for a median period of 49 months. Their ESA and low-dose iron supplement dosages were adjusted to maintain their hemoglobin $(\mathrm{Hb})$ concentrations in the $10-11 \mathrm{~g} / \mathrm{dl}$ range in accordance with Japanese guidelines. The Kaplan-Meier method, log-rank tests, and Cox proportional hazards models were used to perform the statistical analyses. The patients were divided into 3 groups according to their serum ferritin levels: a serum ferritin $<50 \mathrm{ng} / \mathrm{ml}$ group; a $50-100 \mathrm{ng} / \mathrm{ml}$ group; and a $>100 \mathrm{ng} / \mathrm{ml}$ group. Results: During the median follow-up period of 49 months, there were 55 deaths. The multivariate analysis showed no significant associations between the ferritin level groups and all-cause mortality or cardiovascular (CV) events, and the Kaplan-Meier analysis showed no significant differences among the 3 ferritin level groups in all-cause mortality and CV event rates. However, the multivariate analysis revealed that age, CRP level and a history of previous CV disease were independently associated with all-cause mortality, while diabetes, previous CV disease, and iron administration were independently associated with $\mathrm{CV}$ events. Conclusion: The results of this study revealed no significant associations of MHD patients between the ferritin ranges and all-cause mortality or CV events. Thus, the adverse clinical outcomes in these patients were independently associated with other markers and not with their serum ferritin levels.
\end{abstract}

\section{Keywords}

Anemia, Ferritin, Hemodialysis, Mortality 


\section{Introduction}

Anemia and iron metabolism dysregulation are common in patients on maintenance hemodialysis (MHD) [1], and they have long influenced their quality of life [2]. The annual iron loss attributable to dialysis therapy is thought to be $1-2$ g. As a result, MHD patients tend to develop iron deficiency [3], and erythropoiesis-stimulating agents (ESAs) and iron replacement therapy are used to treat anemia. However, the optimal iron index values in MHD patients remain unknown, and iron management standards based on serum ferritin levels, which are an index of stored iron, vary among the several guidelines that have been published. A serum ferritin level $\leq 100 \mathrm{ng} / \mathrm{ml}$ and a transferrin saturation (TSAT) value $\leq 20 \%$ are the criteria that must be met to initiate iron replacement therapy [4]. The Japanese Society for Dialysis Therapy (JSDT) guidelines recommend a lower serum ferritin level than most Western guidelines [5] [6] [7] [8] [9].

Karaboyas et al. have recently demonstrated a trend for serum ferritin levels to increase after implementation of a new bundled payment system in the US, where the median serum ferritin level was $601 \mathrm{ng} / \mathrm{ml}$ in 2009 and $887 \mathrm{ng} / \mathrm{ml}$ in 2012 [10]. Kuragano et al. conducted a prospective cohort study in Japanese MHD patients in which they made repeated serum ferritin measurements and they found that the risk of death and/or adverse events was higher in the group whose ferritin levels were kept high and in the group that exhibited large fluctuations in serum ferritin levels [11]. In their study, a high ferritin level was defined as $>100 \mathrm{ng} / \mathrm{ml}$, based on the mean and median serum ferritin levels (127 and $129 \mathrm{ng} / \mathrm{ml}$, respectively) measured during the study period, suggesting the existence of international differences in the serum ferritin levels for the anemia management in MHD patients.

According to the reports of lower serum ferritin in Japanese MHD patients than in other countries [2], of increased serum ferritin levels in the presence of inflammation [12], and of generally less inflammation in Japanese MHD patients as evidenced by lower C-reactive protein (CRP) levels than in Western countries [13], we provided iron treatment to MHD patients to test hypothesis that it is better to maintain lower serum ferritin levels as a means of preventing inflammation due to excess iron loading and to maintain efficient iron use. The aim of this study was to investigate the relationship between the iron status on anemia treatment and patient survival rates in a cohort of Japanese MHD patients.

\section{Patients and Methods}

\subsection{Study Design}

This retrospective, observational cohort study was conducted at Towa Hospital (Tokyo, Japan).The study subjects were recruited from among 156 patients who had been routinely dialyzed via an arteriovenous fistula in the dialysis unit for at least 6 months during the period from May 2013 to December 2016. The study 
protocols were approved by the institutional review board of Towa Hospital (No. 11) and carried out in accordance with the ethical principles of the Declaration of Helsinki guidelines for medical research involving human subjects. Written informed consent was obtained from every subject. MHD patients with malignancy, active inflammation, liver cirrhosis, gastrointestinal bleeding, valvular heart disease, or severe illness were excluded and were transferred to another dialysis unit for intensive care.

All patients were on thrice-weekly HD sessions. Blood pressure (BP) was measured with a mercury sphygmomanometer with the patient in the supine position after resting for 10 to $15 \mathrm{~min}$, and mean values for the 1-month period preceding enrollment were used in the statistical analysis. Dry weight was targeted to achieve a normotensive edema-free state. Evidence of a history of previous cardiovascular (CV) disease was collected from the medical records. Diabetes was defined as a history or diagnosis of diabetes and/or a fasting plasma glucose concentration $>126 \mathrm{mg} / \mathrm{dl}, \mathrm{HbAlc}$ concentration $>6.5 \%$, or prescription of glucose-lowering agents [14].

Anemia was treated by adjusting the dose of ESA to obtain a hemoglobin $(\mathrm{Hb})$ concentration goal of $10-11 \mathrm{~g} / \mathrm{dl}$, and a serum ferritin level $<50 \mathrm{ng} / \mathrm{dl}$ was used as the criterion for initiating iron administration [15].

\subsection{Data Collection}

The demographic and clinical data recorded on enrollment included age, sex, body mass index (BMI) calculated by dividing body weight by height squared $\left(\mathrm{kg} / \mathrm{m}^{2}\right)$, primary renal disease, comorbidities, and medications. Coronary artery disease was recorded as positive when there was a history of angioplasty, coronary artery bypass grafting, myocardial infarction, or angina, and peripheral artery disease was recorded as a history of claudication, ischemic limb loss and/or ulceration, or a peripheral revascularization procedure. On enrollment and every 3 months thereafter laboratory data were measured from fasting blood samples, which were drawn prior to the start of HD on a midweek day.

Blood was collected when $\mathrm{HD}$ was initiated at the beginning of the week. $\mathrm{Hb}$ was measured twice a month, and serum ferritin, iron and total iron-binding capacity (TIBC) were measured once a month. TSAT was calculated from the values of iron and TIBC $($ TSAT $=$ iron/TIBC/100). Blood urea nitrogen, creatinine, albumin, ferritin, TSAT, and CRP levels, and $\mathrm{Hb}$ concentrations were measured by using standard laboratory methods. Body weight was calculated as dry weight defined as the post-dialysis weight of normotensive patients who had no signs of overhydration.

\subsection{Echocardiographic Examination}

Echocardiograms were performed on echocardiography equipment, an Vivid S6 (GE Healthcare, Tokyo, Japan) ultrasound imager equipped with a $2.2 / 4.4 \mathrm{MHz}$ (harmonics) phased-array $3 \mathrm{~S}$ transducer during continuous electrocardiographic 
recording as previously described [16]. Left ventricular systolic function was evaluated based on the ejection fraction (EF), which was calculated by using a modified biplane Simpson's Method from apical two- and four-chamber views [17].

\subsection{Outcome Measures}

The median duration of the study was 49 (31 - 58) months. The data on all-cause mortality and CV event were retrieved from the hospital database and carefully reviewed. The primary endpoint was all-cause mortality, and the secondary endpoint was a CV event, which was identified by hospitalization for myocardial infarction/ischemia, congestive heart failure, pulmonary edema, cerebrovascular disorder, or intervention for peripheral artery disease.

Anemia was treated by adjusting the dose of ESA to obtain a hemoglobin $(\mathrm{Hb})$ concentration goal of $10-11 \mathrm{~g} / \mathrm{dl}$, and a serum ferritin level $<50 \mathrm{ng} / \mathrm{dl}$ was used as the criterion for initiating iron administration. To investigate the relationship between body iron status and outcome, the subjects were divided into 3 groups according to their serum ferritin level: a $<50 \mathrm{ng} / \mathrm{ml}$ group, a $50-100 \mathrm{ng} / \mathrm{ml}$ group, and a $>100 \mathrm{ng} / \mathrm{ml}$ group. The survival rates, HRs, and causes of death during the follow-up period were compared among the groups.

\subsection{Statistical Analysis}

Baseline descriptive data are presented as the medians values and interquartile ranges. One-way analysis of variance was used to compare the groups with respect to normally distributed continuous variables, and the Kruskal-Wallis $\mathrm{H}$ test was used for other skewed continuous variables. The Chi-square test was used to compare nominally scaled variables. Cumulative probabilities of time-to-event curves were estimated by using the Kaplan-Meier product-limit function, and differences among the curves were tested by the log-rank test. The Cox proportional hazards model was used to estimate the hazard ratios (HRs) and $95 \%$ confidence interval $(95 \% \mathrm{CI}$ ) for outcome in terms of exposure variable using univariate and multivariate analyses. In multivariate analysis, the model was adjusted according to relevant covariates: age, sex, dialysis vintage, diabetes, a history of previous CV disease, BMI, albumin, CRP, Hb, users of ESA, and iron. Because the values of serum ferritin that were not normally distributed and were log-transformed before performing the above parametric analysis. Two-tailed $\mathrm{p}$ values less than 0.05 were considered to indicate a statistically significant difference. The analyses were performed with the JMP for Windows software program (version 11, SAS Institute, Cary, N.C., USA).

\section{Results}

\subsection{Baseline Characteristics of the Study Population}

A total of 156 patients were enrolled in this study. After excluding 6 patients because of missing data, 150 patients were included for the final analyses. The most 
common cause of end-stage renal disease was diabetes (48.7\%), and it was followed by chronic glomerulonephritis (20.7\%). The baseline characteristics of the patients overall and in the 3 groups divided by serum ferritin level are summarized in Table 1 . Of the 150 patients, 99 were males and 51 were females. Median (interquartile range) patient age was 69 (62 - 77) years, and median dialysis vintage was 65 (6 - 131) years. Median values were $10.5 \mathrm{~g} / \mathrm{dl}$ for $\mathrm{Hb}, 18.2 \%$ for TSAT and $41.5 \mathrm{ng} / \mathrm{ml}(24.1$ - 83.4) for serum ferritin.

Age, sex, BMI, dialysis vintage, the presence of diabetes, hypertension, and a history of previous CV disease were comparable among the 3 groups divided by serum ferritin concentrations. There were no significant differences among the 3 groups in $\mathrm{Hb}$ concentrations, serum CRP levels and EF, whereas there was a significant difference in TSAT $(p=0.0010)$ and serum albumin levels $(p=0.0003)$ (Table 1). There were no significant differences among the 3 groups in the proportion of the users of angiotensin receptor blockers and/or angiotens in-converting enzyme inhibitors, ESA, or iron. The distributions of serum ferritin levels (A) and TSAT (B) in the study population are shown in Figure 1.

Table 1. Baseline characteristics of the study population.

\begin{tabular}{|c|c|c|c|c|c|}
\hline & \multirow{2}{*}{$\begin{array}{c}\text { Total } \\
(\mathrm{n}=150)\end{array}$} & \multicolumn{3}{|c|}{ Ferritin } & \multirow[b]{2}{*}{$P$-value } \\
\hline & & $\begin{array}{c}<50 \mathrm{ng} / \mathrm{ml} \\
(\mathrm{n}=89)\end{array}$ & $\begin{array}{c}50-100 \mathrm{ng} / \mathrm{ml} \\
\quad(\mathrm{n}=31)\end{array}$ & $\begin{array}{l}>100 \mathrm{ng} / \mathrm{ml} \\
\quad(\mathrm{n}=30)\end{array}$ & \\
\hline Age (years) & $69(62-77)$ & $67(62-76)$ & $69(64-78)$ & $70(63-80)$ & 0.6575 \\
\hline Male (\%) & 68.0 & 73.0 & 67.7 & 53.3 & 0.1351 \\
\hline Dialysis vintage (months) & $65(4-131)$ & $71(20-151)$ & $32(2-129)$ & $47(3-124)$ & 0.1133 \\
\hline Diabetes (\%) & 48.7 & 49.4 & 48.4 & 46.7 & 0.9655 \\
\hline Previous CVD (\%) & 38.7 & 31.5 & 51.6 & 46.7 & 0.0842 \\
\hline Hypertension (\%) & 82.0 & 83.1 & 83.9 & 76.7 & 0.6939 \\
\hline BMI $\left(\mathrm{kg} / \mathrm{m}^{2}\right)$ & $21.4(19.2-24.1)$ & $21.5(19.2-25.1)$ & $21.2(19.0-23.9)$ & $21.4(19.0-23.9)$ & 0.6631 \\
\hline Hemoglobin (g/dl) & $10.5(9.8-11.1)$ & $10.5(9.8-11.1)$ & $10.5(9.9-11.2)$ & $10.3(9.4-10.9)$ & 0.3526 \\
\hline TSAT (\%) & $18.2(13.0-26.0)$ & $15.0(11.0-21.9)$ & $21.0(14.9-28.0)$ & $21.4(16.5-28.6)$ & 0.0010 \\
\hline Ferritin (ng/ml) & $41.5(24.1-83.4)$ & $26.6(21.1-37.7)$ & $71.2(60.5-83.1)$ & $144.9(125.0-205.3)$ & $<0.0001$ \\
\hline Albumin (g/dl) & $3.9(3.6-4.1)$ & $3.9(3.7-4.2)$ & $3.7(3.1-3.9)$ & $3.8(3.6-4.1)$ & 0.0003 \\
\hline $\mathrm{CRP}(\mathrm{mg} / \mathrm{dl})$ & $0.18(0.10-0.48)$ & $0.18(0.10-0.46)$ & $0.20(0.09-0.52)$ & $0.19(0.11-0.55)$ & 0.8773 \\
\hline $\mathrm{EF}(\%)$ & $67(60-73)$ & $67(60-72)$ & $68(53-73)$ & $67(60-75)$ & 0.8224 \\
\hline ARB and/or ACEi (\%) & 64.7 & 65.2 & 61.3 & 66.7 & 0.8972 \\
\hline ESA (\%) & 92.7 & 94.4 & 87.1 & 93.3 & 0.4025 \\
\hline Iron use iv and/or oral (\%) & 18.0 & 15.7 & 29.0 & 13.3 & 0.1911 \\
\hline
\end{tabular}

Data are expressed as median (interquartile range) or percentage of patients. CVD = cardiovascular disease; $\mathrm{BMI}=$ body mass index; TSAT $=$ transferrin saturation; $\mathrm{CRP}=\mathrm{C}$-reactive protein; $\mathrm{EF}=$ ejection fraction; $\mathrm{ARB}=$ angiotensin receptor blocker; $\mathrm{ACEi}=$ angiotensin-converting enzyme inhibitor; $\mathrm{ESA}=$ erythropoiesis-stimulating agent. 


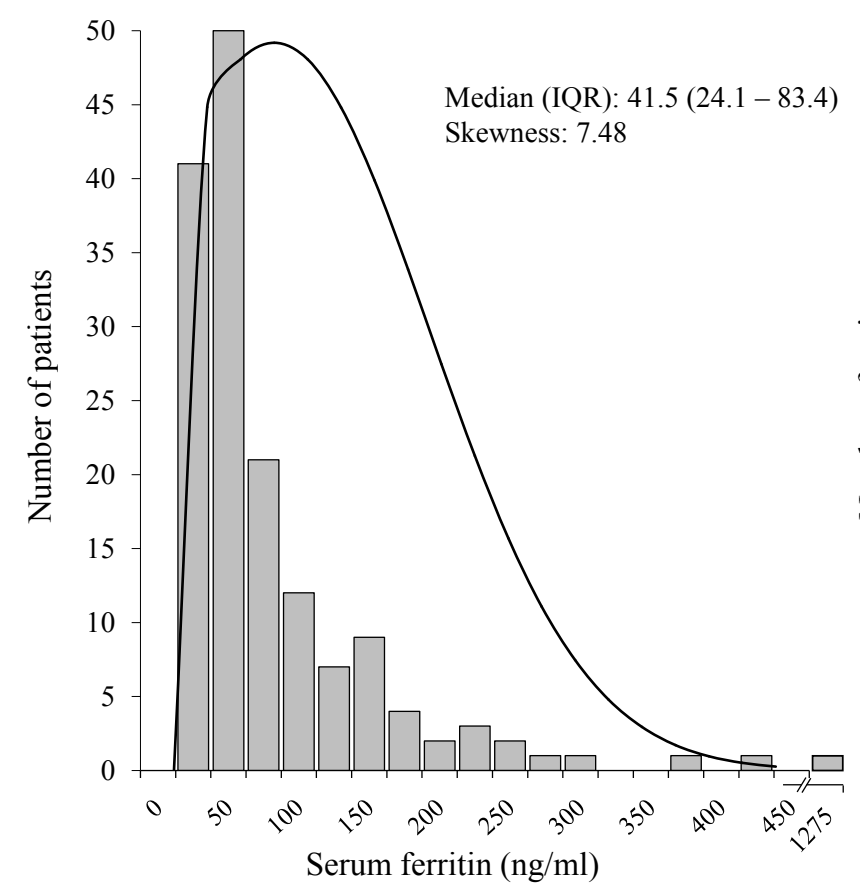

(a)

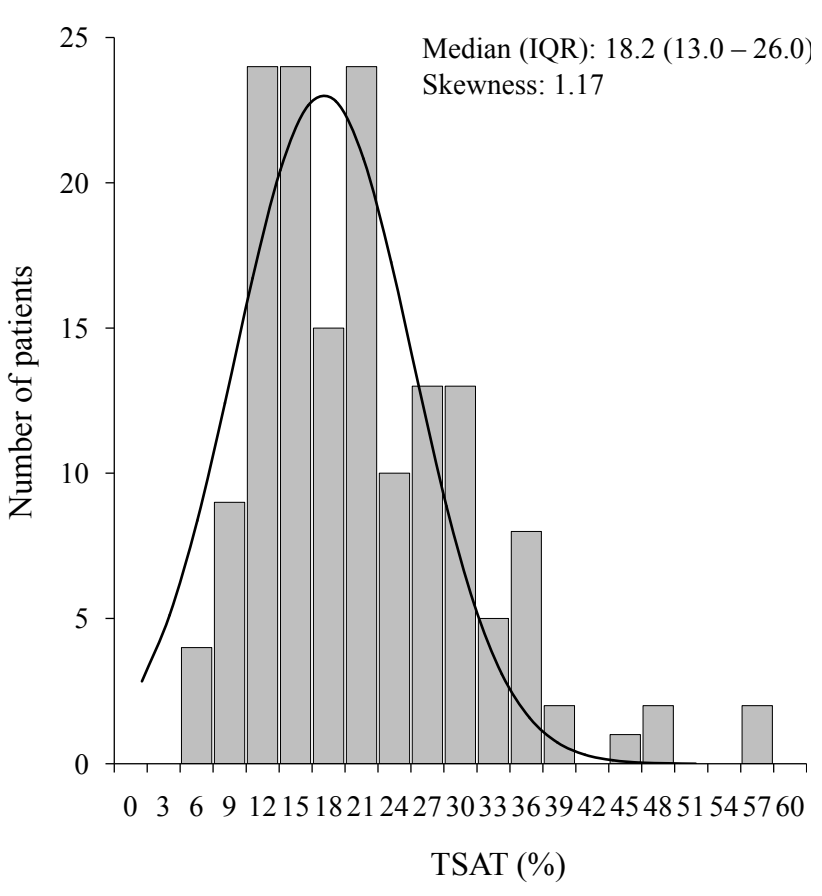

(b)

Figure 1. Distribution of serum ferritin concentrations in the study population.

\subsection{Primary Outcome}

During the median follow-up period of 49 months, there were 55 deaths. The main causes of death during the follow-up period were $\mathrm{CV}$ disease (23 patients) and infection-related disorders (19 patients). Most (61\%) of the patients who died from CV disease were in the group with serum ferritin levels $<50 \mathrm{ng} / \mathrm{ml}$.

We estimated the HRs for all-cause mortality in comparison with the reference group (ferritin $<50 \mathrm{ng} / \mathrm{ml}$ ). The HRs in the univariate and multivariate analyses in the total cohort are shown in Table 2. Multivariate analysis showed no significant associations between all-cause mortality and any of serum ferritin level groups. The Kaplan-Meier analysis showed no significant differences among the 3 ferritin level groups (Figure 2).

When the confounders were used as continuous variables, the multivariate Cox proportional hazard analysis revealed that age (HR 1.10; CI 1.05 - 1.14), CRP (HR 1.64; CI 1.27 - 2.12), and a history of previous CV disease (HR 4.49; CI 2.46 - 8.44) were independently associated with all-cause mortality.

\subsection{Secondary Outcome}

There were 34CV events during the median follow-up period of 49 months and they consisted of 19 coronary artery disease, 8 cerebrovascular infarction, and 7 peripheral artery disease.

We estimated the HRs for CV events by using serumferritin categories with $<50 \mathrm{ng} / \mathrm{ml}$ as the reference group. The HRs in the univariate and multivariate analyses are shown in Table 2 . There were no significant associations between 


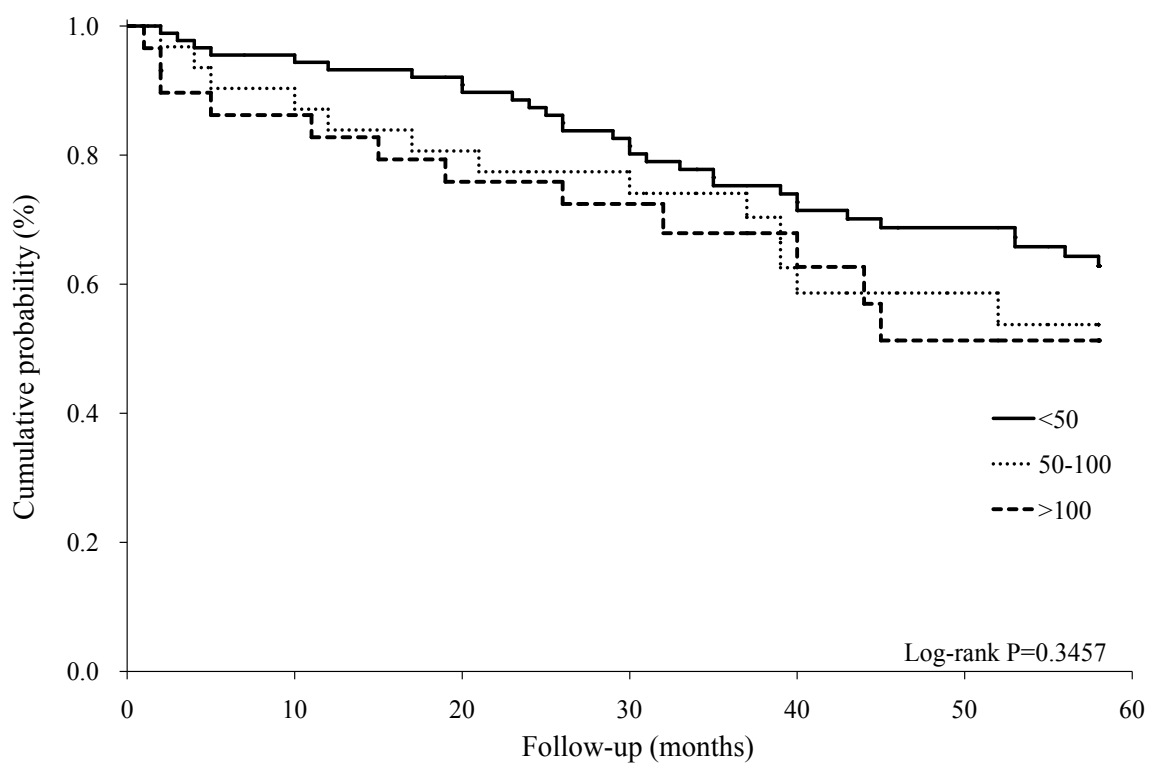

Figure 2. Kaplan-Meier curve for all-cause mortality according to baseline serum ferritin concentrations.

Table 2. Associations of serum ferritin categories with all-cause mortality and cardiovascular $(\mathrm{CV})$ events.

\begin{tabular}{|c|c|c|c|c|c|}
\hline \multirow{2}{*}{ Outcomes } & \multirow{2}{*}{ Ferritin categories } & \multicolumn{2}{|c|}{ Univariate analysis } & \multicolumn{2}{|c|}{ Multivariate analysis } \\
\hline & & $\mathrm{HR}$ & $95 \% \mathrm{CI}$ & HR & $95 \% \mathrm{CI}$ \\
\hline \multicolumn{6}{|c|}{ All-cause mortality } \\
\hline & $<50 \mathrm{ng} / \mathrm{ml}$ & 1.00 & Referent & 1.00 & Referent \\
\hline & $50-100 \mathrm{ng} / \mathrm{ml}$ & 1.40 & $0.71-2.63$ & 1.36 & $0.59-3.05$ \\
\hline & $>100 \mathrm{ng} / \mathrm{ml}$ & 1.56 & $0.77-2.97$ & 1.24 & $0.55-2.64$ \\
\hline \multicolumn{6}{|c|}{ CV events } \\
\hline & $<50 \mathrm{ng} / \mathrm{ml}$ & 1.00 & Referent & 1.00 & Referent \\
\hline & $50-100 \mathrm{ng} / \mathrm{ml}$ & 0.80 & $0.34-1.66$ & 0.48 & $0.17-1.23$ \\
\hline & $>100 \mathrm{ng} / \mathrm{ml}$ & 0.75 & $0.28-1.69$ & 0.67 & $0.23-1.69$ \\
\hline
\end{tabular}

Adjusted for age, sex, dialysis vintage, diabetes mellitus, prior CVD, body mass index, albumin, CRP, hemoglobin, ESA, and iron.

the serum ferritin ranges and CV events in the 3 ferritin level groups. The Kaplan-Meier analysis showed $\mathrm{t}$ no significant differences in the 3 ferritin level groups (Figure 3).

When the confounders were used as continuous variables, the multivariate Cox proportional hazard analysis revealed that diabetes (HR 3.04; CI 1.51 6.43), a history of previous CV disease (HR 3.12; CI 1.57 - 6.32) and iron administration (HR 3.13; CI 1.41 - 6.82) were independently associated with CV events. 


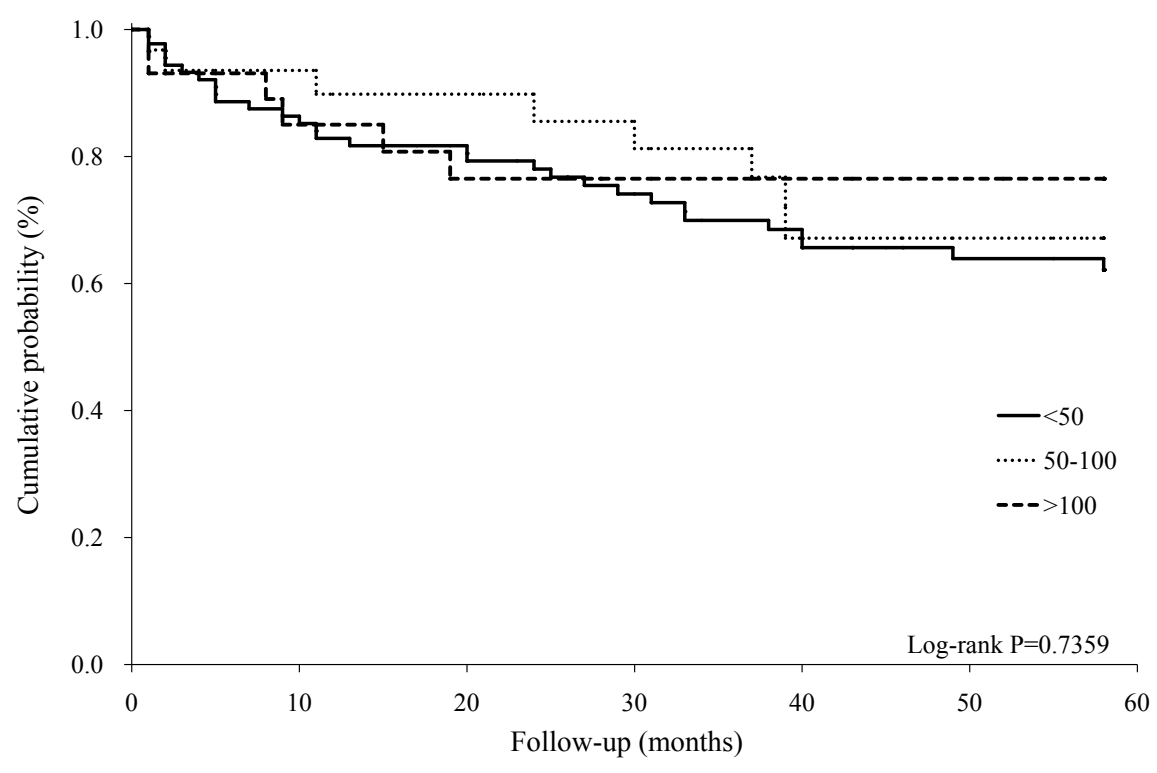

Figure 3. Kaplan-Meier curve for cardiovascular events according to baseline serum ferritin concentrations.

\section{Discussion}

We investigated the relationship between the serum ferritin levels and adverse clinical outcomes in MHD patients. The results of this study showed no significant associations between any of the ferritin level ranges and all-cause mortality and $\mathrm{CV}$ event rates. The multivariate analysis revealed that age, high CRP levels, and preexisting $\mathrm{CV}$ disease were independently associated with all-cause mortality, and that diabetes, previous CV disease, and iron administration were independently associated with $\mathrm{CV}$ events. These findings suggest that the adverse clinical outcomes were independently associated with other markers and not with their serum ferritin levels in MHD patients.

Hasuike et al. found that serum ferritin levels $>100 \mathrm{ng} / \mathrm{mL}$ were associated with higher mortality risk in a cohort of 90 Japanese MHD patients than among subjects with lower ferritin levels [18]. Recently, Kuragano et al. conducted a prospective cohort study of 1086 Japanese MHD patients in which they made repeated serum ferritin measurements and they found that the risk of death and/or adverse events was higher in the group whose ferritin levels were kept high and in the group that exhibited large fluctuations in ferritin levels [11]. In their study, a high ferritin was defined as $>100 \mathrm{ng} / \mathrm{ml}$, based on the mean and median serum ferritin levels (127 and $79 \mathrm{ng} / \mathrm{ml}$, respectively) measured during the study period.

The prevailing iron management standards for dialysis patients in Western countries are found in the Kidney Disease Outcomes Quality Initiative (K/DOQI) guidelines, which state that there is insufficient evidence to recommend routine administration of intravenous (IV) iron if the serum ferritin level is greater than $500 \mathrm{ng} / \mathrm{ml}$ [7], and in the European Renal Best Practice guidelines, which state that if the serum ferritin level is greater than $800 \mathrm{ng} / \mathrm{ml}$, IV 
iron administration should be discontinued [9]. In contrast, the JSDT states that $\leq 100 \mathrm{ng} / \mathrm{ml}$ of serum ferritin and $\leq 20 \%$ of TSAT' are the criteria for initiating iron replacement therapy [4]. Thus, there are considerable international differences in serum ferritin concentrations and associations between serum ferritin concentration and adverse outcomes, and they may have affected the upper limit of serum ferritin concentration in the management of anemia in MHD patients.

A recent study by Park et al. showed that the groups with high serum ferritin levels $(>142.6 \mathrm{ng} / \mathrm{ml}$ ) had a higher all-cause mortality risk than the group with lower serum ferritin levels, and that the association between serum ferritin levels and mortality risk was independent of systemic inflammation and nutritional status in incident HD patients by including CRP as one of the covariates in the Cox model [12]. The median serum ferritin in a Korean HD cohort was 213 $\mathrm{ng} / \mathrm{mL}$, much lower than in US HD patients, but slightly higher than in Japanese HD patients [1] [4]. The study by Park et al. [12] may be of clinical importance, because the results suggest a possible direct effect of ferritin independent of inflammation. However, their study does not resolve the issue of whether systemic inflammation affects the association between serum ferritin levels and mortality risk.

Shoji et al. recently performed an observational cohort study in which they used data from 2606 Japanese HD patients who participated in the Dialysis Outcomes and Practice Patterns Study (DOPPS) [19]. After adjustment for relevant confounding factors, they found a U-shaped association between serum ferritin levels and all-cause mortality in the group with low CRP levels, a relationship that was not significant in the high-CRP group. In contrast, they found a linear association between serum ferritin levels and CV hospitalization in the low-CRP and high-CRP group. They concluded that serum ferritin levels exhibited different patterns of association with all-cause mortality in MHD patients according to whether inflammation was present, whereas their association with $\mathrm{CV}$ hospitalization was similar regardless of their inflammatory status.

Ogawa et al. attempted to identify the optimal serum ferritin level in the TSAT $\geq 20 \%$ group, in which iron use efficiency was considered to have been maintained, and they used the Kaplan-Meier method and Cox proportional hazards models to compare outcomes in 3groups classified according to their serum ferritin levels [20]. Both analyses showed a significantly better outcome in group 2 (TSAT $\geq 20 \%$ and serum ferritin $30-80 \mathrm{ng} / \mathrm{ml})(p=0.013)$. Their analysis using conventional Coxproportional hazards models revealed that both low and high serum ferritin levels in the TSAT $\geq 20 \%$ group were associated with a poorer outcome than when serum ferritin levels were in the intermediate range. Moreover, since TSAT and serum ferritin levels may be associated with variations in the doses of ESA and iron; they may have been important confounders during the period of this study.

There were no significant differences in the associations between serum ferritin levels and all-cause mortality and CV events in the present study. Our study population had better nutritional status, because the median serum albumin lev- 
el was $3.9(3.6-4.1)$. In addition, the median serum CRP level of our subjects was $0.18(0.10-0.48)$, indicating a low incidence of inflammatory events in our study. The presence of inflammation makes it difficult to achieve TSAT $\geq 20 \%$ and results in higher serum ferritin levels [21], suggesting that it is essential to reduce inflammatory responses. Usually, a decrease in serum ferritin level and decrease in TSAT results in a $\mathrm{Hb}$ concentration in the iron deficiency range, but an increase in both parameters does not necessarily result in a higher $\mathrm{Hb}$ level. Therapeutic intervention by ESA and iron administration alters the anemic and iron storage parameters in a complex manner, particularly in renal anemia.

The multivariate analysis in the present study revealed that age, high CRP levels, and preexisting CV disease were independently associated with all-cause mortality, and that diabetes, preexisting $\mathrm{CV}$ disease, and iron administration were independently associated with CV events. Ma and Zhao performed a meta-analysis to evaluate the impact of various patient characteristics on the risk of mortality in HD patients [22], and the results showed that various risk factors, including age, diabetes, preexisting $\mathrm{CV}$ disease, and serum ferritin levels were associated with increased risk of all-cause mortality and cardiac death. They concluded that multiple markers and factors influence the risk of mortality and cardiac death in HD patients. However, their data for several indices in support of this conclusion are insufficient. Furthermore, a study of the effects of race and ethnicity on the risk of cardiac death in HD patients should be conducted. Hence, further large-scale studies are needed to verify their findings.

\section{Conclusion}

The results of this study demonstrated no associations between the serum ferritin levels and all-cause mortality and CV event rates in a cohort of Japanese MHD patients. Our findings suggest that the optimal serum ferritin level in MHD patients may be considerably lower than currently recommended in the several guidelines. Adverse clinical outcomes were independently associated with other markers and not with serum ferritin levels. Further studies are needed to determine whether the results of this observational study can be translated into the management of anemia in MHD patients.

\section{Study Limitations}

This study had several limitations. Because this was a retrospective and observational study and the number of enrolled patients was small, there may be other confounding factors that remain to be analyzed. Furthermore, because the patient's management was dependent on the attending physician, there were variations in patient management in addition to using different targets for serum ferritin and $\mathrm{Hb}$ levels.

\section{Recommendation}

Multiple markers and factors contribute to the risk of mortality and cardiac 
death in MHD patients. Multivariate analyses should be conducted using risk factors including iron indices to investigate mortality risk of MHD patients.

\section{Acknowledgements}

The authors are very grateful to medical staff, who understood the clinical importance of this study and provided high-quality data in Towa Hospital. This study was in part supported by a grant from the Japan Promotion Society for Cardiovascular Disease.

\section{Conflict of Interest}

All authors declare no conflict of interests in this work.

\section{Author's Contributions}

MS and HK carried out the data collection. $\mathrm{NH}$ and KT discussed the results of statistical analysis. $\mathrm{NH}$ and $\mathrm{KN}$ wrote the manuscript. All authors read and approved the final manuscript.

\section{References}

[1] Masakane, I., Taniguchi, M.., Nakai, S., Tsuchida, K., Goto, S., Wada, A., Ogata, S., Hasegawa, T., Hamano, T., Hanafusa, N., Hoshino, J., Minakuchi, J. and Nakamoto, H. (2018) Annual Dialysis Data Report 2015, JSDT Renal Data Registry (JRDR). Renal Replacement Therapy, 4, 19.

[2] Pisoni, R.L., Bragg-Gresham, J.L., Young, E.W., Akizawa, T., Asano, Y., Locatelli, F., Bommer, J., Cruz, J.M., Kerr, P.G., Mendelssohn, D.C., Held, P.J. and Port, F.K. (2004) Anemia Management and Outcomes from 12 Countries in the Dialysis Outcomes and Practice Patterns Study (DOPPS). American Journal of Kidney Diseases, 44, 94-111. https://doi.org/10.1053/j.ajkd.2004.03.023

[3] Nakanishi, T., Hasuike, Y., Otaki, Y., Nanami, M. and Kuragano, T. (2015) Dysregulated Iron Metabolism in Patients on Hemodialysis. Contribution to Nephrology, 185, 22-31.

[4] Yamamoto, H., Nishi, S., Tomo, T., Masakane, I., Saito, K., Nangaku, M., Hattori, M., Suzuki, T., Morita, S., Ashida, A., Ito, Y., Kuragano, T., Komatsu, Y., Sakai, K., Tsubakihara, Y., Tsuruya K., Hayashi, T., Hirakata, H. and Honda, H. (2017) 2015 Japanese Society for Dialysis Therapy: Guidelines for Renal Anemia in Chronic Kidney Disease. Renal Replacement Therapy, 3, 36. https://doi.org/10.1186/s41100-017-0114-y

[5] Madore, F., White, C.T., Foley, R.N., Barrett, B.J., Moist, L.M., Klarenbach, S.W., Culleton, B.F., Tonelli, M., Manns, B.J., Canadian Society of Nephrology. (2008) Clinical Practice Guidelines for Assessment and Management of Iron Deficiency. Kidney International Supplement, 110, S7-S11. https://doi.org/10.1038/ki.2008.269

[6] Kidney Disease: Improving Global Outcomes (KDIGO) Anemia Work Group (2012) KDIGO Clinical Practice Guidelines for Anemia in Chronic Kidney Disease. Kidney International Supplement, 2, 279-335.

[7] Kliger, A.S., Foley, R.N., Goldfarb, D.S., Goldstein, S.L., Johansen, K., Singh, A. and Szczech, L. (2013) KDOQI US Commentary on the 2012 KDIGO Clinical Practice Guideline for Anemia in CKD. American Journal of Kidney Diseases, 62, 849-859. 
https://doi.org/10.1053/j.ajkd.2013.06.008

[8] Macginley, R., Walker, R. and Irving, M. (2013) KHA-CARI Guideline: Use of Iron in Chronic Kidney Disease Patients. Nephrology (Carlton), 18, 747-749. https://doi.org/10.1111/nep.12139

[9] Locatelli, F., Barany, P., Covic, A., De Francisco, L., Goldsmith, D., Horl, W., London, G., Vanholder, R., Van Biesen, W., ERA-EDTA ERBP Advisory Board. (2013) Kidney Disease: Improving Global Outcomes Guidelines on Anaemia Management in Chronic Kidney Disease: A European Renal Best Practice Position Statement. Nephrology Dialysis Transplantation, 28, 1346-1359. https://doi.org/10.1093/ndt/gft033

[10] Karaboyas, A., Zee, J., Morgenstern, H., Nolen, J.G., Hakim, R., Kalantar-Zadeh, K., Zager, P., Pisoni, R.L., Port, F.K. and Robinson, B.M. (2015) Understanding the Recent Increase in Ferritin Levels in United States Dialysis Patients: Potential Impact of Changes in Intravenous Iron and Erythropoiesis-Stimulating Agent Dosing. Clinical Journal of American Society of Nephrology, 10, 1814-1821. https://doi.org/10.2215/CJN.02600315

[11] Kuragano, T., Matsumura, O., Matsuda, A., Hara, T., Kiyomoto, H., Murata, T., Kitamura, K., Fujimoto, S., Hase, H., Joki, N., Fukatsu, A., Inoue, T., Itakura I. and Nakanishi, T. (2014) Association between Hemoglobin Variability, Ferritin Levels, and Adverse Events/Mortality in Maintenance Hemodialysis Patients. Kidney International, 86, 845-854. https://doi.org/10.1038/ki.2014.114

[12] Park, K.S., Ryu, G.W., Jhee, J.H., Kim, H.W., Park, S., Lee, S.A., Kwon, Y.E., Kim, Y.L., Ryu, H.J., Lee, M.J., Han, S.H., Yoo, T.H., Kim, Y.L., Kim, Y.S., Yang, C.W., Kim, N.H., Kang, S.W. and Park, J.T. (2015) Serum Ferritin Predicts Mortality Regardless of Inflammatory and Nutritional Status in Patients Starting Dialysis: A Prospective Cohort Study. Blood Purification, 40, 209-217. https://doi.org/10.1159/000438819

[13] Kawaguchi, T., Tong, L., Robinson, B.M., Sen, A., Fukuhara, S., Kurokawa, K., Canaud, B., Lamiere, N., Port, F.K. and Pisoni, R.L. (2011) C-Reactive Protein and Mortality in Hemodialysis Patients: The Dialysis Outcomes and Practice Patterns Study (DOPPS). Nephron Clinical Practice, 117, c167-c178.

https://doi.org/10.1159/000320116

[14] Alberti, K.G. and Zimmet, P.Z. (1998) Definition, Diagnosis and Classification of Diabetes Mellitus and Its Complications. Part 1: Diagnosis and Classification of Diabetes Mellitus Provisional Report of a WHO Consultation. Diabetic Medicine, 15, 539-553.

https://doi.org/10.1002/(SICI)1096-9136(199807)15:7\%3C539::AID-DIA668\%3E3.0. CO;2-S

[15] Tsubakihara, Y., Nishi, S., Akiba, T., Hirakata, H., Iseki, K., Kubota, M., Kuriyama, S., Komatsu, Y., Suzuki, M., Nakai, S., Hattori, M., Babazono, T., Hiramatsu, M., Yamamoto, H., Bessho, M. and Akizawa, T. (2010) 2008 Japanese Society for Dialysis Therapy: Guidelines for Renal Anemia in Chronic Kidney Disease. Therapeutic Apheresis and Dialysis, 14, 240-275. https://doi.org/10.1111/j.1744-9987.2010.00836.x

[16] Saito, A., Onuki, T., Echida, Y., Otsubo, S. and Nitta, K. (2014) Fibroblast Growth Factor 23 and Left Ventricular Hypertrophy in Hemodialysis Patients. International Journal of Clinical Medicine, 5, 1102-1110. https://doi.org/10.4236/ijcm.2014.517141

[17] Otterstad, J.E., Froeland, G., St John Sutton, M. and Holme, I. (1997) Accuracy and Reproducibility of Biplane Two-Dimensional Echocardiographic Measurements of 
Left Ventricular Dimensions and Function. European Heart Journal, 18, 507-513. https://doi.org/10.1093/oxfordjournals.eurheartj.a015273

[18] Hasuike, Y., Nonoguchi, H., Tokuyama, M., Ohue, M., Nagai, T., Yahiro, M., Nanami, M., Otaki, Y. and Nakanishi, T. (2010) Serum Ferritin Predicts Prognosis in Hemodialysis Patients: The Nishinomiya Study. Clinical and Experimental Nephrology, 14, 349-355. https://doi.org/10.1007/s10157-010-0288-x

[19] Shoji, T., Niihara, K., Fukuma, S., Fukuhara, S., Akizawa, T. and Inaba, M. (2017) Both Low and High Serum Ferritin Levels Predict Mortality Risk in Hemodialysis Patients without Inflammation. Clinical and Experimental Nephrology, 21, 685-693. https://doi.org/10.1007/s10157-016-1317-1

[20] Ogawa, C., Tsuchiya, K., Kanda, F. and Maeda, T. (2014) Low Levels of Serum Ferritin Lead to Adequate Hemoglobin Levels and Good Survival in Hemodialysis Patients. American Journal of Nephrology, 40, 561-570.

https://doi.org/10.1159/000370317

[21] Wish, J.B. (2006) Assessing Iron Status: Beyond Serum Ferritin and Transferrin Saturation. Clinical Journal of American Society of Nephrology, Suppl 1, S4-S8. https://doi.org/10.2215/CJN.01490506

[22] Ma, L. and Zhao, S. (2017) Risk Factors for Mortality in Patients Undergoing Hemodialysis: A Systematic Review and Meta-Analysis. International Journal of Cardiology, 238, 151-158. https://doi.org/10.1016/j.ijcard.2017.02.095 